\title{
REVISITING GOLD'S SAFE HAVEN STATUS WITH THE UTILIZATION OF THE INDEX OF IMPLIED VOLATILITY AND THE VALUES OF EXCHANGE TRADED FUNDS
}

\section{DIMITRIOS PANAGIOTOU1*}

1. University of loannina, loannina, Greece

* Corresponding Author: Dimitrios Panagiotou, Department of Economics, University of loannina, loannina, Greece $₫$ dpanag@uoi.gr

\begin{abstract}
The coronavirus pandemic is a health and economic crisis which has placed an immense strain on the world's financial system. Hence, amidst the (still ongoing) Covid-19 pandemic, the objective of this work is to investigate the role of gold as as a hedge or safe haven with the use of exchange traded funds. The present work employs the implied volatility index of gold share options (GVZ), the net asset value of the price per share of the US Oil Fund options (USO) and the value of the Currency Share Euro Trust (FXE). The statistical tool utilized is the quantile regressions methodology. Data are daily observations from June 2008 to May 2021. The empirical results reveal that gold's implied volatility decreases significantly (or it is not statistically different than zero), under changes in the average returns and/or under extreme market declines in FXE and USO. According to the aforementioned findings, gold could be an investment vehicle to serve as a hedge and or a safe haven asset. The present study is the first one to employ quantile regressions (QR) along with gold's implied volatility and the prices of exchange traded funds (ETFs) in order to investigate gold's hedge and/or safe haven properties.
\end{abstract}

\section{Introduction}

The coronavirus pandemic is a health and economic crisis which has placed an immense strain on the world's financial system. Amid the spread of Covid-19 around the globe, stock and bond markets worldwide have experienced significant losses and unprecedented volatility. As an example, on March 9th, 2020, Brent crude oil prices collapsed, falling by as much as $31 \backslash \%$, which was the largest single-day drop since the U.S. invaded Iraq in 1991. Figures 1 and 2 present the evolution of oil prices and the euro/dollar (EUR/USD) exchange rates, for the month of March, where the pandemic have had the biggest impact around the globe. Between March 6th and March 20th, oil prices fell by almost 50\%. ${ }^{1}$ For the same time period, the EUR/USD exchange rate fell by almost $7 \%$, then increased by $5 \%$, and fell again by the same percentage points.

According to the leverage hypothesis expressed by Christie (1982), a negative return in the value of the stock increases the financial leverage, making this way the stock riskier and as a

\footnotetext{
1 Crude oil was hit really hard: a price war between Saudi Arabia and Russia caused prices to plunge,
} and energy prices typically decline when economic activity slows down. 
result the underlying volatility increases. While major banks were heavily fortified after the financial crisis in 2008, stock and bond markets have shown signs of turbulence as investors get rid of anything with a hint of risk. The key question is, which investment(s) serve as a hedge or safe haven in periods of uncertainty and extreme stock market volatility.

In the finance literature, gold has been found to act both as a hedge as well as a safe haven asset Anand and Madhogaria, 2012; Baur and Lucey, 2010; Beckmann et al., 2015; Reboredo and Rivera-Castro, 2014). ${ }^{2}$ Gold is known to be frequently uncorrelated with other assets (Baur and Lucey, 2010) and is said to be a zero-beta asset (Mccown and Zimmerman, 2006). Accordingly, gold seems to be appropriate to be considered as a hedge and/or a safe haven for financial assets or portfolios. The reason is that, in contrast to many other commodities, gold is known to be durable, easily recognizable, storable, portable, divisible, and easily standardized (Baur and McDermott, 2010).

Figure 1: WTI Crude oil prices (source: Oilprice.com)

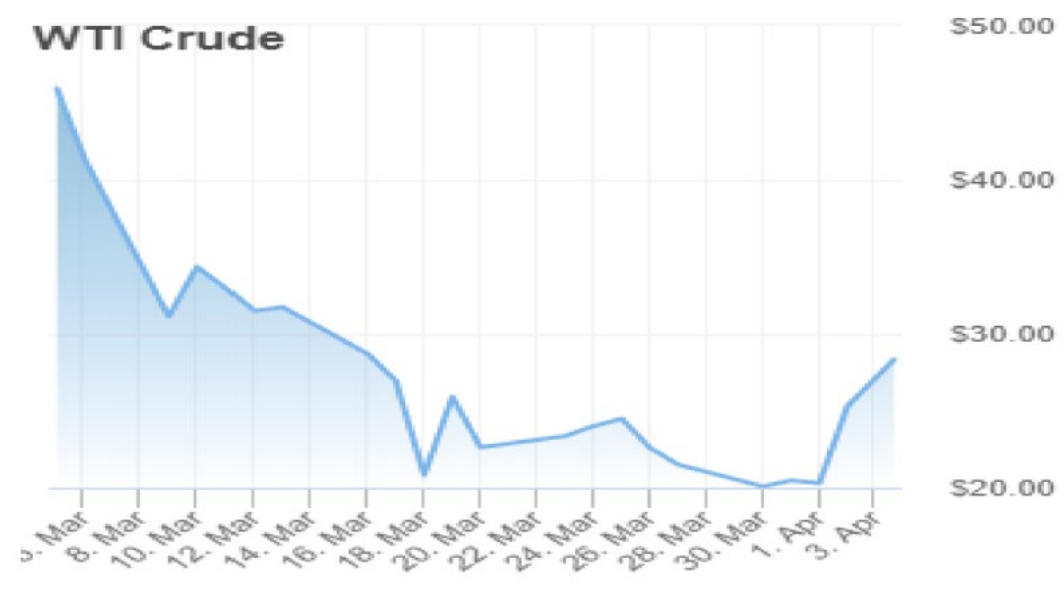

The main objective of this work is to revisit gold's safe haven and/or hedge properties - against movements in the oil prices as well as against the EUR/USD exchange rate - with the utilization of the implied volatility of gold shares options along with the values of the exchange traded funds (ETFs) of oil and EUR/USD. In doing so, it employs the econometric tool of the parametric quantile regressions (QR). QR modelling provides more flexibility and presents significant advantages over existing methodologies. The main advantages are:

i. QR can capture a possible non-linear relationship between the dependent and the independent variable, even though the estimated regression function is linear at a given quantile,

ii. $\quad$ QR do not require any specific assumptions about the error distribution.

Accordingly, the quantile regressions approach is robust to non-normal errors and to outliers, and

iii. the derived QR estimator is asymptotically normal, it has an analytical variancecovariance estimator and it is invariant to monotonic transformations of the data.

2 On the 25th of February of 2020, stock markets around the world presented significant losses and gold prices climbed to levels not seen since February 2013, the price of gold ascended to its highest level in seven years, as worries about the coronavirus led investors to seek a safe place for their capital. 
Figure 2: Euro/dollar exchange rate (source: Exchangerates.org.uk)

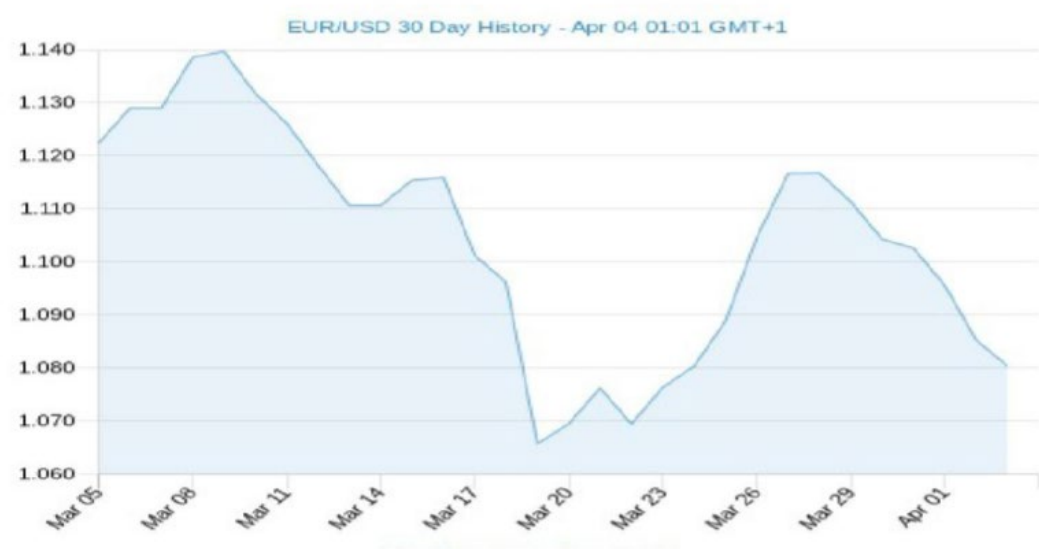

Worldwide, gold and oil are major commodities and their price movements have important implications for the real economy as well as the financial markets. Gold and oil prices may drive the prices of other commodities (Sari et al., 2010) and can often act as an indicator of the health of the economy. In times of a financial crisis or high rates of inflation, many investors turn to gold in order to "seek for shelter". On the other hand, in periods of economic stability, investors are more likely to turn to more speculative investments, such as stocks, bonds and real estate. Concurrently, significant oil price hikes have been blamed for economic recessions, trade deficits, high inflation, high investment uncertainty and low stock and bond values. The value of crude oil stocks may have far broader implications with regard to financial stability and to macroeconomic performance (Fousekis, 2019).

Gold has been tested to have safe haven as well as hedge properties against oil price movements. Ciner et al. (2013) used daily data between January 1990 to June 2010, for the US and the UK, in order to investigate how and under what circumstances each of the five major financial assets, stocks, bonds, oil, gold, and the US dollar, provide a hedge or a safe haven function to each other. The authors detected that gold acts as a safe haven for most assets, except of oil. Baffes (2007) examined the pass-through of crude oil price changes to the price of thirty-five internationally traded primary commodities. The findings indicated that the price of precious metals, and in particular gold, responded strongly to the crude oil price. Hammoudeh and Yuan (2008) employed volatility models, from the generalized autoregressive conditional heteroskedasticity (GARCH) family, in order to study the impact of oil prices on gold returns and the volatility of gold returns. The EGARCH model (exponential general autoregressive conditional heteroskedastic), revealed that oil price shocks had an insignificant effect on gold returns. On the other hand, oil price shocks significantly reduced the volatility of gold returns. Soytas et al. (2009) studied the relationship between oil prices and gold, silver and other macroeconomic variables for the case of Turkey. A vector autoregressive model used in order to examine the short-run and long-run relationships between metal prices and the price of oil. Based on daily data, they reported that the world oil price had no predictive power over precious metal prices, such as gold. Narayan et al. (2010) examined the long-term relationship between gold and oil prices, both spot and futures, at different maturities. The findings revealed that investors used gold as a hedge against inflation and that oil and gold could be used to mutually predict prices. Using daily data, Zhang and Wei (2010) studied the cointegration relationship, linear and non-linear Granger causality and price discovery for crude oil and gold markets. Their evidence suggested that: i) crude oil and gold markets shared similar price trends, ii) there was a longterm equilibrium relationship between the two markets, iii) there was linear Granger causality from the oil price to the gold price but not vice versa and, iv) there was no evidence of non- 
linear Granger causality. Sari et al. (2010) employed impulse response functions and forecast error variance decompositions in order to analyse the effect of oil price shocks on precious metal returns and the US dollar/euro exchange rate. The empirical evidence indicated that precious metal markets responded positively and significantly to oil prices, but only in the short-run, with the effect dissipating over the long-run. Reboredo (2013a) assessed the role of gold as a hedge and/or safe haven against oil price movements. The author employed a testing approach based on using copulas. Empirical findings indicated that gold cannot hedge against oil price movements but it can act as an effective safe haven against extreme oil price movements.

The relationship between changes in the price of gold and the US dollar (USD) has also been investigated in the literature. Capie et al. (2005) assessed the role of gold as a hedge against the US dollar by estimating elasticities for a model of the responsiveness of gold to changes in the exchange rate. Capie confirmed the positive relationship between USD depreciation and the price of gold, making gold an effective hedge against the USD. Sjaastad (2008) found that currency appreciations or depreciations had strong effects on the price of gold. Joy (2011) analysed whether gold could serve as a hedge or an investment safe haven with the use of multivariate GARCH model of dynamic conditional correlations. The empirical results suggested that gold has been an effective hedge but a poor safe haven against the USD. Baur and McDermott (2010) found that gold and the US dollar act as safe haven assets during periods of market stress. Reboredo (2013c) assessed the role of gold as a safe haven or hedge against the US dollar (USD) using copulas to evaluate average and extreme market dependence between gold and the USD. The empirical evidence revealed positive and significant average dependence between gold and USD depreciation which is consistent with the fact that gold can act as a hedge against USD rate movements. Furthermore, the findings suggested symmetric tail dependence between gold and USD exchange rates, indicating that gold can act as a safe haven against extreme USD rate movements. This paper contributes in two ways to the existing literature on gold as a hedge and/or safe haven against currency depreciation. The strength of gold's safe haven effect is most clearly illustrated in specific crisis episodes where the reaction of gold is more pronounced than that of other potential safe haven assets.

All of the aforementioned studies, as well as the relevant literature in finance, utilize the price of gold and the price of oil as well as the USD exchange rate, in order to test gold's safe haven and/or hedge status against the aforementioned assets. Hence, despite the fact that the abovementioned channels well establish the safe haven and/or hedge status of gold and its use for portfolio diversification, no study to date has analysed the co-movement of gold prices against oil prices and the USD exchange rate with the employment of gold's implied volatility index.

Against this background, the objective of this work is to revisit the subject and and draw inferences on gold's investment status (hedge and/or safe haven) with the employment of daily prices of the US Oil exchange traded fund (USO), the EUR/USD exchange traded fund (FXE) and the implied volatility index of gold (GVZ), as produced by the Chicago Board Options Exchange (CBOE) ${ }^{3}$.

To the best of our knowledge, this is the first study to employ gold's implied volatility and the prices of exchange traded funds in order to investigate gold's hedge and/or safe haven properties. The index of implied volatility reflects the market expectations for the future volatility of the underlying equity index. Implied volatility is often referred as the investors' fear

\footnotetext{
3 The results make a timely contribution as during the writing of this manuscript financial markets around the globe are experiencing unprecedented volatility and declining returns due to the economic problems stemming from the coronavirus pandemic.
} 
gauge. Fear and uncertainty largely drive the volatility. As fear and uncertainty grow bigger, the index of implied volatility gets higher.

The contribution of this article to the existing literature is threefold: i) it uses of the implied volatility of gold in order to test gold's ability to act as a financial safe haven and/or a hedge, ii) it employs exchange traded funds, namely the USO (oil price) and the FXE (US dollar/Euro exchange rate), and iii) it utilizes the QR approach as the econometric tool in order to draw inferences about financial safe havens and hedges.

In the era of globalization, correlations among most types of assets has increased dramatically, leading this way to increased price and variation volatility (Beckmann et al., 2015). As a consequence, investors seek out to diversify their portfolio and include investments that will act as a safe haven during times of crisis. The latter is extremely useful for portfolio managers who want to maintain a diversified portfolio and who want investment protection against downside risk. Gold, is known to be frequently uncorrelated with other assets (Bredin et al., 2017; Hood and Malik, 2013). Based on the empirical findings, this study makes inferences about gold's safe haven properties in the global financial system. The latter is extremely useful for portfolio managers who want to maintain a diversified portfolio and who want investment protection against downside risk. In addition, it is useful for policy makers, given the association between gold and macroeconomic variables, such as interest rates and exchange rates (Reboredo, 2013b; Soytas et al., 2009).

In what follows section 2 presents the analytical framework, section 3 the data and section 4 the empirical models and results. Section 5 offers conclusions and suggestions for future research.

\section{Quantile Regressions Methodology}

The quantile regressions (QR) can potentially describe the entire conditional distribution of the response. QR measure the marginal effects of explanatory variables by estimating regression coefficients and they express the marginal effects of the explanatory variable on the explained variable in a specific quantile. Therefore, quantile regressions make it possible to analyze the levels of the impact of the explanatory variable on the explained variable in different quantiles.

QR can be viewed as a generation of OLS to a collection of models with different conditional quantile functions. The ordinary least squares (OLS) estimates minimize $\sum_{i} e_{i}^{2}$, the sum of the squared error terms and they enable us to estimate models for conditional mean functions. Comparatively quantile regression minimize a weighted sum of the positive and negative error terms that gives asymmetric penalties (1-q)|ei| for over-prediction and q|ei| for underprediction. If the quantile q differs from 0.5 , there is an asymmetric penalty, with increasing asymmetry as q approaches 0 or 1 .

Quantile regressions do not assume a particular parametric distribution for the response, nor do they assume a constant variance for the response, unlike OLS regression. Although its computation requires linear programming methods, the quantile regression estimator is asymptotically normally distributed.

The quantile regression model (Koenker and Bassett Jr, 1978; Koenker and Hallock, 2001) offers considerable flexibility in empirical research since it disposes with the common slope assumption, by allowing the effect of a change in the independent variable to vary along the conditional distribution of the dependent variable. Hence, quantile regression approach estimates the relationship between the independent variable and the dependent variable in different quantiles in order to have a complete picture of the overall distribution. 
In the quantile regression approach the t sample quantile can be obtained by solving the following minimization problem:

$$
\hat{q_{T}}=\underset{i=1}{\arg \min _{q} R k} \sum \rho_{T}\left(Y_{i} \quad q\right)
$$

where $0<\tau<1, \rho_{T}$ is the tilted absolute value function and $k=\operatorname{dim}\left(\beta_{q}\right)$. Now, let's assume that the conditional $T$-quantile function is $Q_{Y \mid X}(T)=X \beta_{\tau}$. Given a sample of observations $\left(Y_{i}\right.$, $X_{i}$ ) with $\mathrm{i}=1,2, \ldots \mathrm{N}$ as well as the distribution function of $Y$, the estimated value of $\beta_{\text {T }}$ can be obtained by solving:

$$
\hat{\beta}_{\boldsymbol{T}}=\underset{T}{\arg \min _{\beta}} \quad R k \sum \rho_{T}\left(Y_{i} \quad X_{i} \beta_{T}\right)
$$

The minimization problem of equation 2 can be reformulated and solve efficiently as a linear programming problem:

$$
\hat{\beta}_{\tau}=\min _{\beta_{\varepsilon} \in R^{k}} \sum_{i: Y_{i} \geq X_{i} \beta_{\tau}} \tau\left|Y_{i}-X_{i} \beta_{\tau}\right|+\sum_{i: Y_{i} \geq X_{i} \beta_{\tau}}(1-\tau)\left|Y_{i}-X_{i} \beta_{\tau}\right|
$$

For $\tau \in(0,1)$ and under some regularity conditions $\hat{\beta}_{\tau}$ is asymptotically normal:

$$
\sqrt{N}\left(\hat{\beta}_{\tau}-\beta_{\tau}\right) \stackrel{d}{\rightarrow} N\left(0, \tau(1-\tau) D^{-1} \Omega_{x} D^{-1}\right)
$$

where

$$
D=E\left(f_{y}(X \beta) X X^{\prime}\right) \text { and } \Omega_{x}=E\left(X^{\prime} X\right),
$$

with $f_{y}$ being the probability distribution function. Inference for quantile regression parameters can be made with the regression rank-score tests or with the bootstrap methods. The latter is being utilized by the present study.

\section{Data Description}

The data for the empirical analysis are daily observations on the implied volatility index of gold Share options (GVZ), the net asset value of the price per share of the US Oil Fund options (USO) and the value of the Currency Share Euro Trust (FXE). Data cover more than a decade, spanning from June 3rd, 2008 to May 11th, 2021. Data observations include the global financial and economic crisis in 2008 (collapse of Lehman Brothers in September 2008), the financial crisis in the EU 2012-2015 (Greece, Italy, Portugal, Spain, Ireland) as well as the recent economic crisis due to the Covid-19 pandemic.

The Gold Volatility Index (GVZ) measures the market's expectation of thirty-day volatility of gold prices. The GVZ is derived by applying the VIX methodology to options on SPDR Gold Shares (GLD). The VIX methodology was developed by the CBOE in order to measure the market's expectation of short-run (thirty days) forward looking volatility of the underlying asset. In the case of gold, the CBOE volatility index (GVZ) is based on the performance of the GLD, 
where GLD is an exchange-traded fund (ETF) that represents fractional, undivided interest in the SPDR Gold Trust, which primarily holds gold bullion. The performance of GLD is intended to reflect the spot price of gold, less fund expenses. GLD first began trading on the New York Stock Exchange in November 2004. On the other hand, the Chicago Board Options Exchange started calculating and distributing the Gold VIX (GVZ) in June of 2008.

Future volatility (implied volatility) is the most significant variable in the option pricing model and is often referred as the investors' "fear gauge". In the case of gold (GVZ), market participants can improve certainty with respect to the gold price trends by looking at the implied volatility of gold (GVZ).

USO is an exchange traded fund offering investors exposure to crude oil price changes. The objective of the USO is the daily percentage changes of its net asset value to reflect the daily percentage changes of the price of the WTI, light sweet crude oil. ${ }^{4}$ Its benchmark is the near month oil futures contract traded on the New York Merchantile Exchange (NYMEX). The United States Oil Fund was founded in April of 2006.

FXE is an exchange traded fund with holdings of physical euros on demand deposits in euro denominated bank accounts. ${ }^{5}$ Accordingly, the daily percentage changes of the FXE intent to reflect the daily percentage changes of the \$US/Euro exchange rate, less fund expenses. CBOE began trading FXE options in January of 2008.

Figure 3 presents the evolution of the natural logarithms of the GVZ, the FXE and the USO for the specified time period. It appears that FXE and USO move together for most of the time, with the exception of the time period between 2010-2012, with FXE being more volatile than USO. For the time period that corresponds to the Covid-19 pandemic, the implied volatility of gold exhibits a downward trend whereas the USO and FXE appear to move upwards. In general, the two-time series (FXE and USO) appear to generally move in opposite directions with the implied volatility of gold (GVZ).

Figure 3: Natural logarithms of GVZ, FXE and USO (3 June 2008 to 11 May 2021)

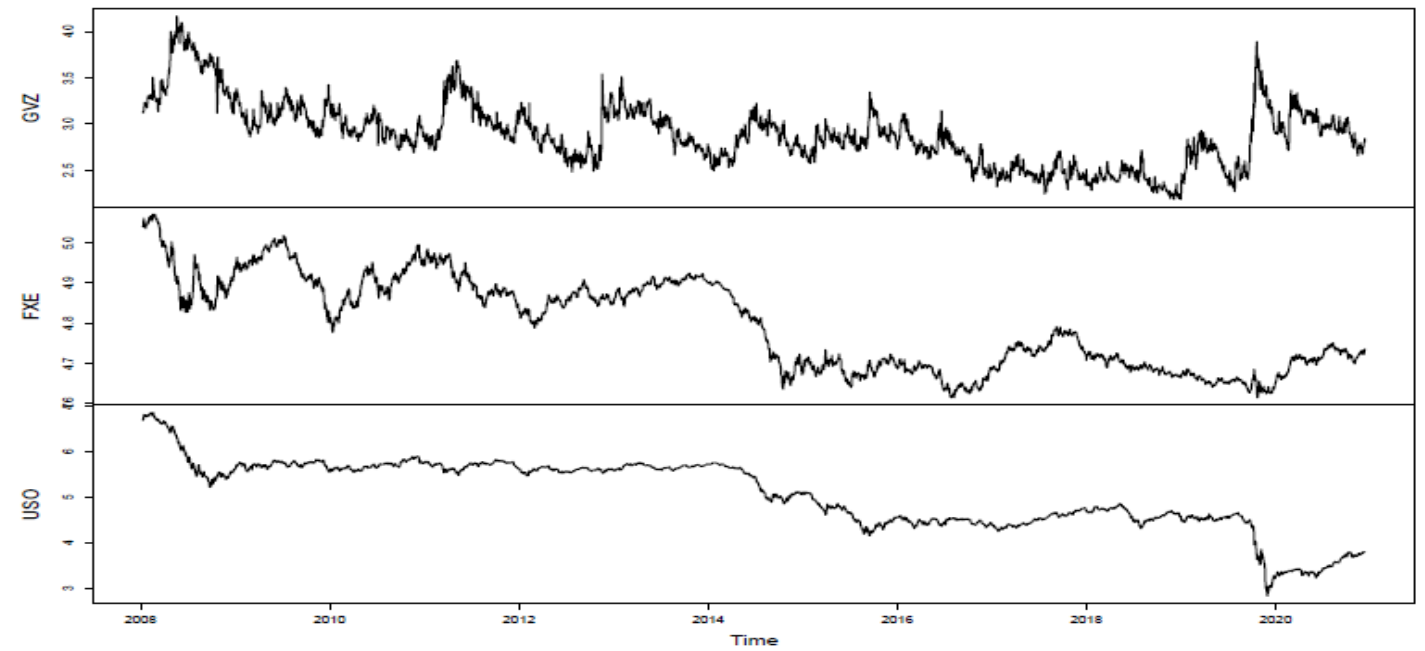

4 West Texas intermediate (WTI), also known as Texas light sweet, is a grade of crude oil used as a benchmark in oil pricing.

5 The Euro is the currency of nineteen (19) European Union countries. 
Table 1 presents the descriptive statistics and tests on the distributions of the percentage changes (rates of change) for GVZ, FXE and USO. The rates of change (or returns) are defined as $d \ln X=\ln X t-\ln X t-1$, where $X$ is GVZ, FXE and USO, respectively.

The empirical results for the statistical significance of skewness, kurtosis and normality have been obtained with the use of the tests by D'Agostino (1970), Anscombe and Glynn (1983) and Shapiro and Wilk (1965), respectively. GVZ returns exhibit a positive and statistically significant kurtosis, pointing to leptokurtic distributions. The distribution of GVZ returns exhibits positive and significant skewness whereas that of USO is negative and statistically significant. The distribution of FXE returns exhibits positive skewness and it is statistically significant. For all three-time series (returns of GVZ, FXE and USO), the null of normality is strongly rejected at any reasonable level of significance.

\section{Table 1: Descriptive Statistics for dl n (FXE) and dln (USO)}

\begin{tabular}{lrrr}
\hline Statistics & dln (GVZ) & dln (FXE) & DIn (USO) \\
\hline Min & -0.44596 & -0.03123 & -0.29189 \\
Max & -0.48074 & 0.03605 & 0.15415 \\
Mean & -0.00008 & -0.00009 & -0.00089 \\
Skewness & 0.80755 & 0.04428 & -1.23551 \\
Kurtosis & 10.51509 & 5.66627 & 18.75483 \\
& & & p-values \\
\hline Tests & p-values & p-values & $<0.01$ \\
\hline Skewness & $<0.01$ & $<0.01$ & $<0.01$ \\
Kurtosis & $<0.01$ & $<0.01$ & $<0.01$ \\
\hline Normality & $<0.01$ & $<0.01$ &
\end{tabular}

\section{Empirical Model and Results}

Empirical results are obtained with the estimation of the following relationship

$$
\text { Implied volatility change }=F(\text { price change }) \text {, }
$$

where $F$ is a potentially non-linear and unknown function. Changes in the implied volatility are measured by dlnGVZ. Price changes are measured by dInFXE and dlnUSO, respectively. The three-time series (dInGVZ, dInFXE and dInUSO) have been tested and the null hypothesis of non-stationarity has been rejected.

In order to empirically examine if gold serves as a safe haven asset, the index of the implied volatility and the negative returns of the independent variables of FXE and USO returns have been employed. A strong (weak) safe haven is defined as an asset that is negatively correlated (uncorrelated) with another investment in periods of extreme market declines. On the other hand, in order to empirically investigate if gold acts as a hedge asset, the implied volatility index of gold and the average rate of returns of the independent variables of FXE and USO exchange traded funds have been utilized. A strong (weak) hedge is defined as an asset that is negatively correlated (uncorrelated) with another investment on average. 
Tables 2 and 3 present the empirical findings for the cases of FXE and USO, respectively. For the case of the exchange traded fund FXE (Table 2), and under average price returns, the values of the estimated parameters are negative and statistically significant up to the 0.6 quantile (with the exception of the 0.2 quantile). Furthermore, for the quantile levels $2 \%, 5 \%$ and $10 \%$ (crash quantiles under average returns), the estimated coefficients assume the highest values, in absolute terms. These findings indicate that gold volatility decreases significantly, in absolute terms, under average returns in the FXE, with the negative response being the highest at the crash quantiles. At the upper quantile levels (0.7 and up), the coefficients are not statistically significant, namely they are not statistically different than zero. These empirical results indicate that the implied volatility of gold does not react to changes in the average returns of the USO. Lastly, the symmetry in all quantile pairs is rejected at the $1 \%$ level of significance, indicating that gold's volatility response differs between the lower and the upper quantiles.

Table 2: Quantile Regression Results for FXE Returns

\begin{tabular}{|c|c|c|}
\hline Quantiles & $\begin{array}{c}\text { Coefficients } \\
\text { (dlnP } \gtrless 0 \text { ) } \\
\text { (hedge column) }\end{array}$ & $\begin{array}{c}\text { Coefficients } \\
(\text { dln } P<0) \\
\text { (safe haven column) }\end{array}$ \\
\hline $2 \%$ & $-0.43779^{*}$ & 3.7641 \\
\hline $5 \%$ & $-0.77062^{* *}$ & 0.24626 \\
\hline $10 \%$ & $-0.45788^{*}$ & -0.18235 \\
\hline $20 \%$ & -0.20025 & -0.13482 \\
\hline $30 \%$ & $-0.37823^{* *}$ & -0.63437 \\
\hline $40 \%$ & $-0.29783^{*}$ & $-1.16325^{* * *}$ \\
\hline $50 \%$ & $-0.45067^{* *}$ & $-1.53245^{* * *}$ \\
\hline $60 \%$ & $-0.34680 *$ & $-1.85001^{* * *}$ \\
\hline $70 \%$ & -0.32732 & $-2.25490^{* * *}$ \\
\hline $80 \%$ & -0.41037 & $-2.83837^{* * *}$ \\
\hline $90 \%$ & -0.28797 & $-3.90704^{* * *}$ \\
\hline $95 \%$ & -0.27919 & $-4.77346^{* * *}$ \\
\hline $98 \%$ & -0.22612 & $-6.54646^{* * *}$ \\
\hline \multirow{2}{*}{ Global equality of parameters: } & p-values & p-values \\
\hline & $<0.01$ & $<0.01$ \\
\hline Test for parameter equality ( $\mathrm{H}_{0}$ : symmetry): & p-values & p-values \\
\hline $2 \%$ and $98 \%$ & $<0.01$ & $<0.01$ \\
\hline $5 \%$ and $95 \%$ & $<0.01$ & $<0.01$ \\
\hline $10 \%$ and $90 \%$ & $<0.01$ & $<0.01$ \\
\hline $20 \%$ and $80 \%$ & $<0.01$ & $<0.01$ \\
\hline $30 \%$ and $70 \%$ & $<0.01$ & $<0.01$ \\
\hline $40 \%$ and $60 \%$ & 0.68 & 0.05 \\
\hline
\end{tabular}

$\left(*^{* *}, * *,{ }^{*}\right): 1 \%, 5 \%$ and $10 \%$ levels of significance, respectively.

Results were obtained with the bootstrap method after 1000 replications.

Under negative returns in FXE, the estimated coefficients are not statistically significant at the lower quantile levels ( $2 \%$ to $30 \%$ ). On the other hand, the estimated values of the parameters are negative and statistically significant from the 0.3 quantile level and up. More specifically, the estimated values of the parameters increase in absolute numbers, as we move at the upper quantile levels, with the highest values realized at the 0.95 and 0.98 quantiles. These findings indicate that the implied volatility of gold decreases significantly as we move at the upper quantile levels, namely as the negative changes in FXE get more extreme (extreme market declines). 
Table 3: Quantile Regression Results for USO Returns

\begin{tabular}{lcc}
\hline Quantiles & $\begin{array}{c}\text { Coefficients } \\
\text { (dlnP } ₹ \text { ) } \\
\text { (hedge column) }\end{array}$ & $\begin{array}{c}\text { Coefficients } \\
\text { (dlnP< }) \\
\text { (safe haven column) }\end{array}$ \\
\hline $2 \%$ & $-0.38695^{* * *}$ & -0.04829 \\
$5 \%$ & $-0.28860^{* *}$ & 0.08129 \\
$10 \%$ & $-0.30881^{* * *}$ & -0.01529 \\
$20 \%$ & $-0.30433^{* * *}$ & $-0.26519^{* * *}$ \\
$30 \%$ & $-0.36140^{* * *}$ & $-0.36701^{* * *}$ \\
$40 \%$ & $-0.35949^{* * *}$ & $-0.37722^{* * *}$ \\
$50 \%$ & $-0.37302^{* * *}$ & $-0.42965^{* * *}$ \\
$60 \%$ & $-0.40273^{* * *}$ & $-0.70915^{* * *}$ \\
$70 \%$ & $-0.46282^{* * *}$ & $-0.73437^{* * *}$ \\
$80 \%$ & $-0.47691^{* * *}$ & $-0.89477^{* * *}$ \\
$90 \%$ & $-0.47986^{* * *}$ & $-0.91227^{* * *}$ \\
$95 \%$ & $-0.44790^{* * *}$ & $-1.16459^{* * *}$ \\
$98 \%$ & $-0.48587^{* * *}$ & $-1.98318^{* * *}$ \\
\hline Global equality of parameters: & $\mathbf{p}$-values & $\mathbf{p}$-values \\
\hline & 0.209 & $<0.01$ \\
\hline Test for parameter equality (Ho: symmetry): & $\mathbf{p}$-values & $\mathbf{p}$-values \\
\hline $5 \%$ and $95 \%$ & 0.29 & $<0.01$ \\
$10 \%$ and $90 \%$ & 0.07 & $<0.01$ \\
$20 \%$ and $80 \%$ & $<0.01$ & $<0.01$ \\
$30 \%$ and $70 \%$ & 0.02 & $<0.01$ \\
$40 \%$ and $60 \%$ & 0.16 & $<0.01$ \\
\hline
\end{tabular}

$(* * *, * * *): 1 \%, 5 \%$ and $10 \%$ levels of significance, respectively.

Results were obtained with the bootstrap method after 1000 replications.

For the case of the exchange traded fund USO (Table 3), and under average price returns in the USO, all the estimated coefficients are negative and statistically significant, at every given quantile level. Furthermore, the null hypothesis of global equality cannot be rejected, suggesting that changes of the implied volatility of gold do not differ statistically at different quantile levels.

Under negative returns in USO, the estimated coefficients are not statistically significant at the lower quantile levels $(2 \%, 5 \%$ and $10 \%)$, namely they are not different than zero. On the other hand, the estimated values of the parameters are negative and statistically significant from the 0.2 quantile level and up. In addition, the estimated values of the parameters increase in absolute numbers, as we move at the upper quantile levels, with the highest values realized at the 0.95 and 0.98 quantiles. These findings indicate that the implied volatility of gold decreases significantly as we move at the upper quantile levels, namely as the negative changes in USO get more extreme (extreme market declines).

The null hypothesis of global equality is rejected at the $1 \%$ level of significance or less, suggesting that changes in the implied volatility of gold differ statistically at different quantile levels. Symmetry in quantile pairs is also rejected, at the $1 \%$ level of significance or less, for all pairs.

The empirical results presented in tables 2-3 need to be examined under the light of previous empirical outcomes. Accordingly, findings in relevant studies have suggested that the price 
of gold increases under currency depreciation (Joy, 2011; Reboredo, 2013c), as well as when oil prices go down (Reboredo, 2013a). These works suggest the possibility of using gold as a hedge against currency and oil movements, and as a safe haven asset against extreme declines in currency and oil prices. The empirical results of the present study indicate that the implied volatility of gold significantly decreases, or at least does not increase, under average as well as under extreme market declines in the exchange traded funds of FXE and USO. According to (Campbell and Hentschel, 1992), bad news brings higher current volatility as well as increases in future volatility, since volatility is highly persistent. This higher volatility raises the required return, resulting this way in a stock price decline. Investors anticipating these declines turn to assets that are less volatile and less risky, minimizing this way the danger of a potential capital loss.

Figure 4: FXE Average

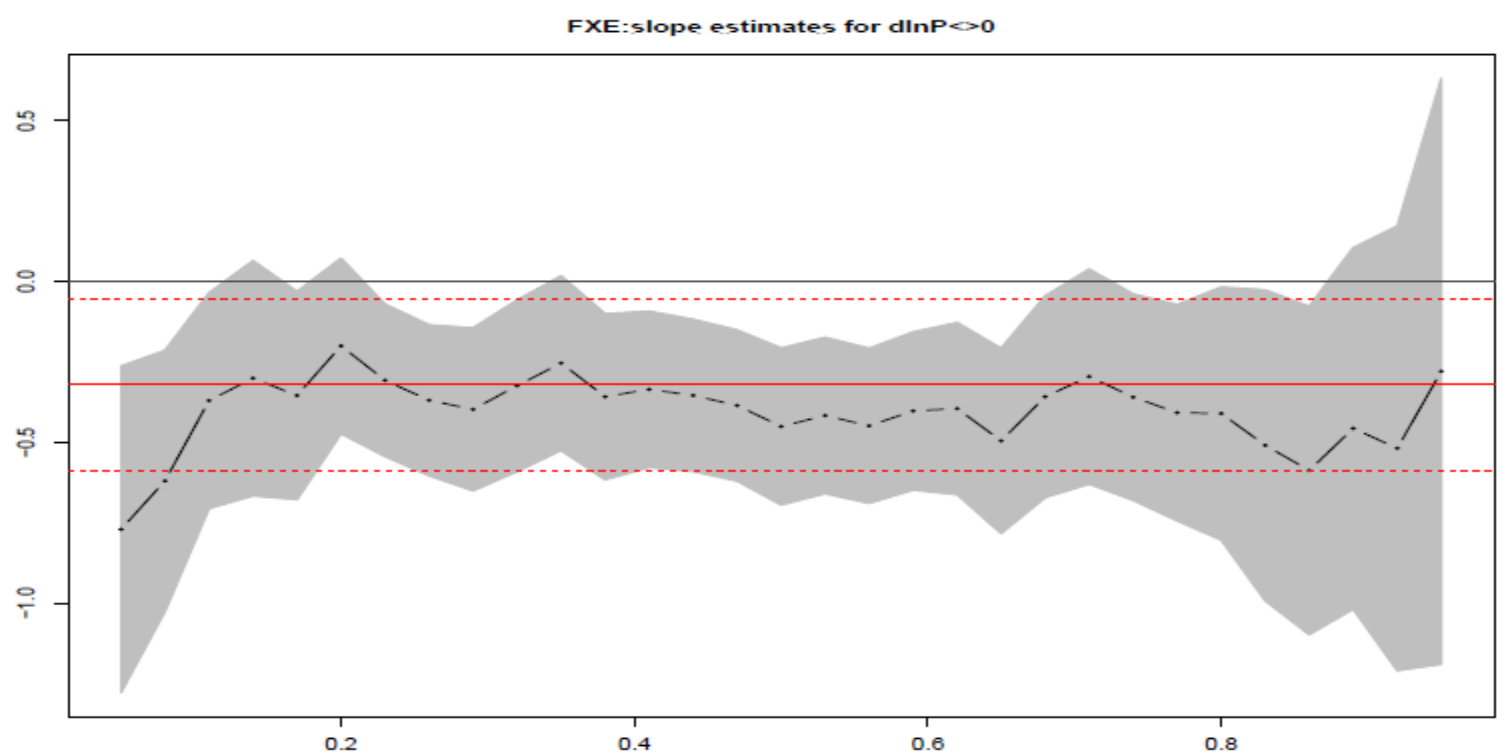

Figure 5: FXE Negative

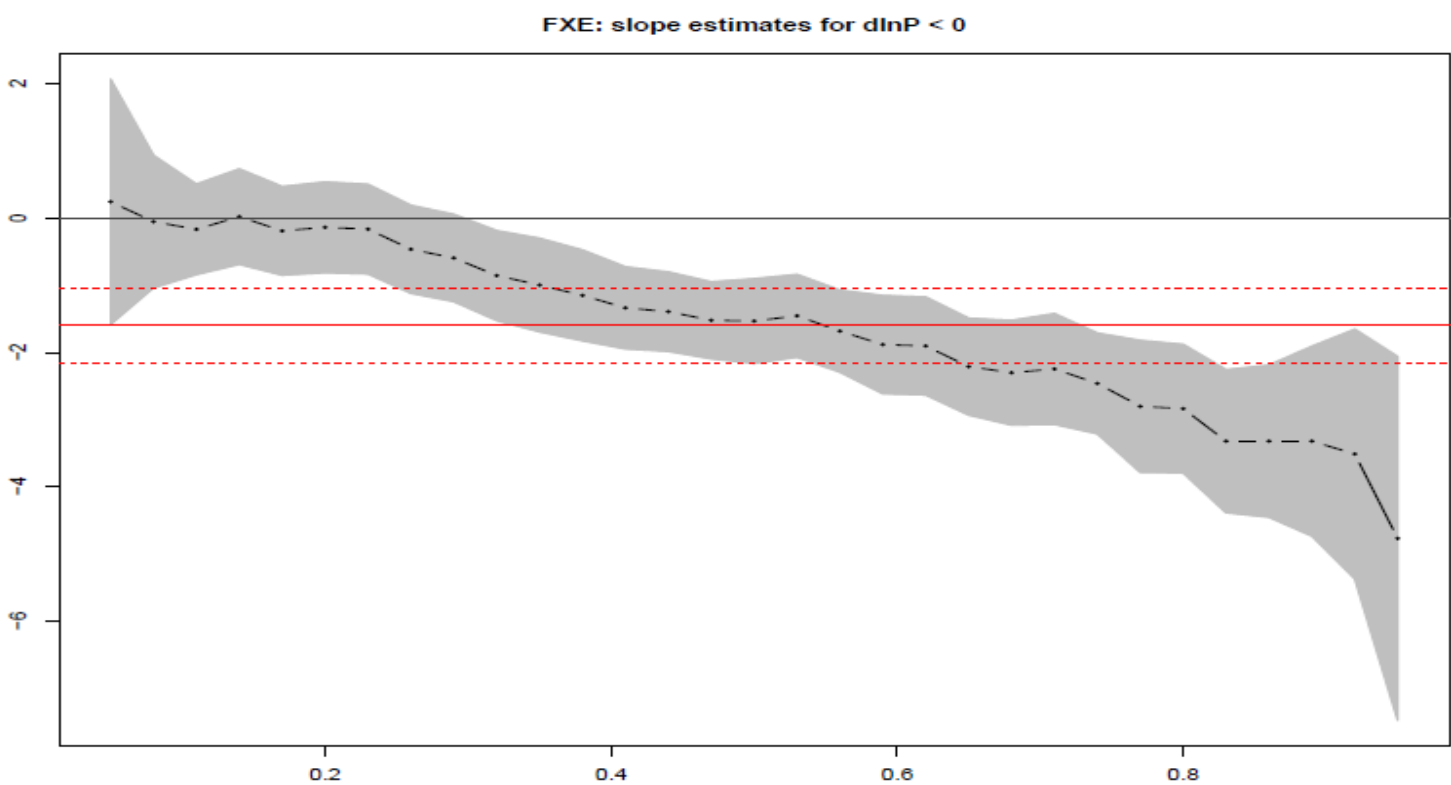


For the case of the USO and under average returns (figure 6), the OLS coefficient is negative, statistical significant, with an estimated value of 0.42 in absolute terms. On the other hand, the estimated slopes of the quantile coefficients are lower, in absolute values, than the OLS coefficient, up to the 0.6 quantile level. Beyond that quantile level, the estimated quantile parameters obtain slightly higher values (in absolute terms) than the OLS coefficient. With a visual inspection, both the QR method as well as the OLS regression would have suggested that gold behaves as a strong hedge. Hence, the OLS parameter performs well, as compared to the QR approach, in predicting the magnitude in changes in gold's implied volatility for given changes in USO values. Under negative returns in USO (figure 7), the OLS coefficient is also negative and statistically significant. The estimated value of the OLS parameter is (approximately) 0.6 in absolute terms. On the other hand, the estimated slopes of the quantile coefficients are not statistically significant up to the 0.1 quantile level. From the 0.15 to 0.6 quantile level, the estimated values of the quantile parameters are lower, in absolute terms, than the OLS coefficient.

Figure 6: Average Returns in USO

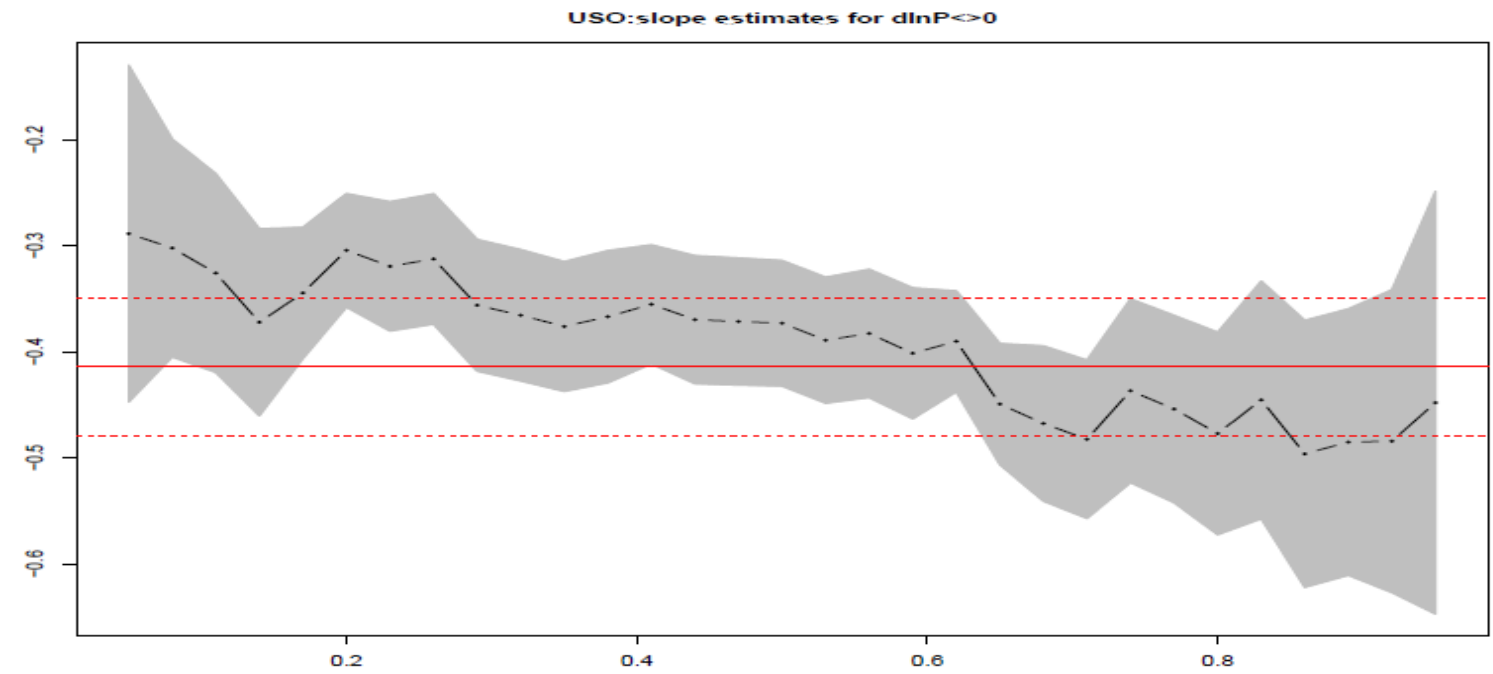

As we move to the upper quantiles, the estimated values of the quantile parameters are higher (in absolute terms) than the OLS coefficient. At the 0.98 quantile, the value of the coefficient of the QR approach is 1.98 in absolute terms, whereas the $95 \%$ lower limit of the confidence interval of the OLS parameter is (approximately) 0.8. The aforementioned findings suggest that the OLS method provides a good estimate of the reaction in gold's implied volatility only for a small range of the quantile levels. In addition, as market declines in USO become more extreme (upper quantiles), the mean of changes in GVZ for given changes in USO, does not capture the true magnitude of changes in GVZ. The reason is that as the QR findings suggest, the decrease in the implied volatility of gold gets bigger and bigger as market declines in USO get more extreme.

For many years, strengthened gold prices, in combination with extreme currency movements, have attracted the attention of investors, risk managers as well as the financial media. In addition, many studies have suggested the possibility of using gold as a hedge against currency movements and as a safe-haven asset against extreme currency movements. The aforementioned fact has been proven to be quite useful for policy makers, given the association between gold and macroeconomic variables, such as interest rates and exchange rates (Reboredo, 2013b; Soytas et al., 2009). Concurrently, prior studies have indicated that gold can act as an effective safe haven against extreme oil price volatility 
and have proposed that portfolio risk managers could use (or use) gold to preserve or to stabilize the purchasing power of oil exporters (Reboredo, 2013b). The empirical results of the present work agree with the findings of the relevant literature so far. Accordingly, these findings suggest that gold could provide financial shelter for investors, during (extreme) market declines in oil prices as as well in the EUR/USD exchange rate, as measured by the values of their respective ETFs. The above findings are extremely useful for portfolio managers who want to maintain a diversified portfolio and who are looking for investment protection against downside risk.

Figure 7: Negative Returns in USO

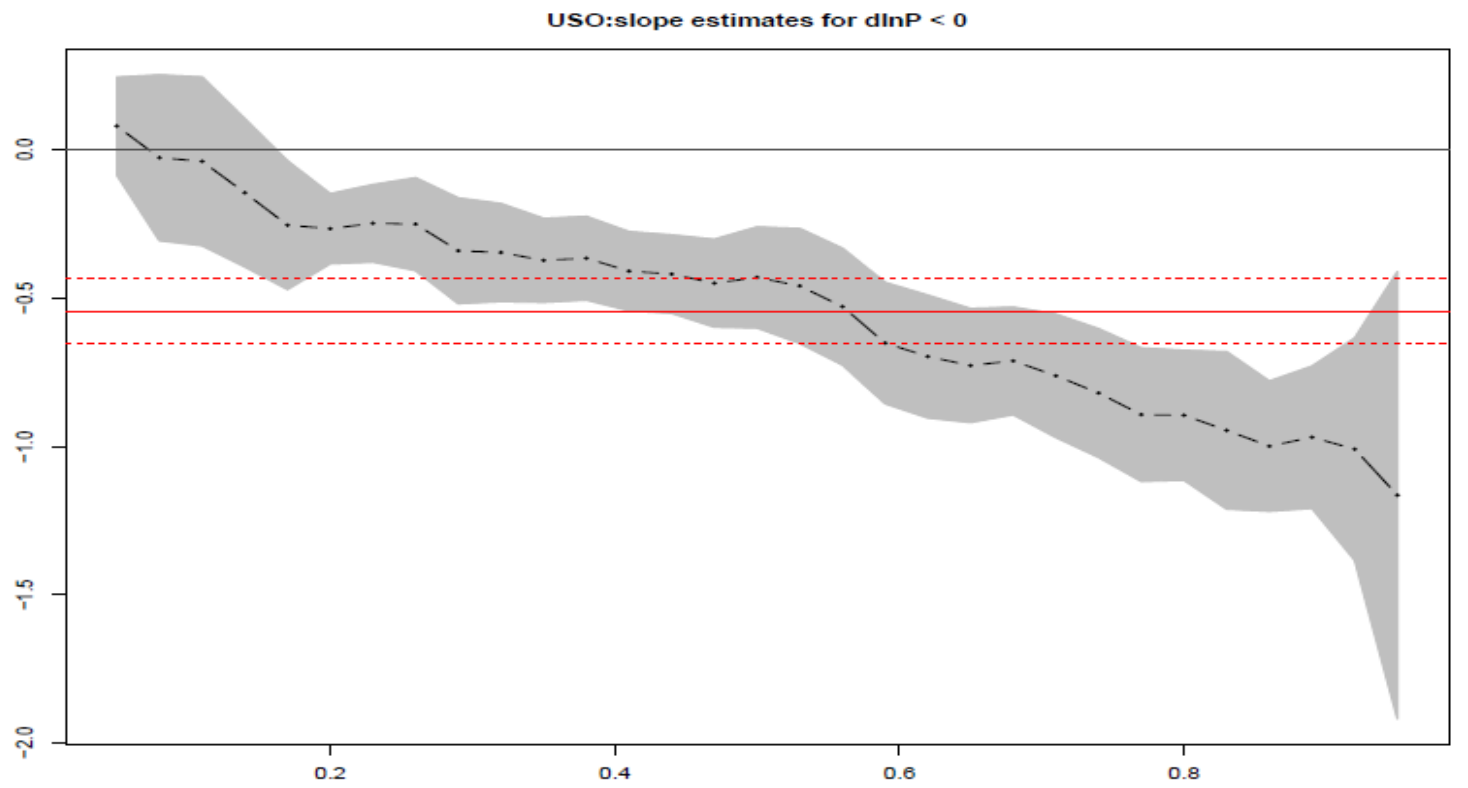

\section{Conclusion}

Amid the (still ongoing) coronavirus pandemic, stock markets around the globe have been experiencing high volatility and unexpected declining returns. As a prime example, on Monday, April 20th of 2020, the price of futures of WTI crude oil went negative for the first time in history. The latter means that traders had to pay buyers to take oil off their hands.6 This happened because there was no place to store all the crude the world is producing but not using due to a collapse in demand.

The objective of this work is to investigate the role of gold as a hedge or safe haven, against oil prices and exchange rates (EUR/USD) movements. In doing so, it employs the implied volatility index of gold share options (GVZ), the net asset value of the price per share of the US Oil Fund options (USO) and the value of the Currency Share Euro Trust (FXE), along with the utilization of the quantile regressions methodology. Using daily data from June 2008 to May 2021, the empirical results reveal that gold's implied volatility decreases significantly (or it is not statistically different than zero), under changes in the average returns and/or under extreme market declines in FXE and USO. The knowledge of the significant reduction in gold's implied volatility under (extreme) changes in FXE and USO returns, might be very valuable for investors and for portfolio managers. Both parties seek for investment protection against risk, particularly in reducing the risk of heavy losses in times of severe market volatility. The results indicate that gold can provide shelter in times of financial uncertainty. 
Implied volatility is the market's expectation about the future realized volatility of the asset under examination and it is often referred as the investors' fear gauge. Volatility levels are largely fear driven: higher levels of fear imply higher levels of volatility. Accordingly, investors can improve certainty by focusing on the volatility. By applying technical analysis to the implied volatility of gold, the present work attempts to improve, or not, the confidence in gold against the exchange traded funds (ETFs) of the crude oil (USO) and exchange rate (EUR/USD). This information will be particularly useful to financial market participants since volatility is readily tradable, with Volatility Index (VIX) on the Chicago Board Options Exchange (CBOE) being the most prominent derivative. Exposures to volatility can be made by investing in VIX futures contract or an Exchange Traded Fund (ETF) on VIX (Hood and Malik, 2013).

The findings of this manuscript are in agreement the majority of the results in the relevant area of the finance literature. These results indicate that gold acts both as a hedge and a safe haven asset. Even though there is no theoretical model that explains why gold is usually referred to as a hedge or a safe heaven in financial markets, the reasons are many. Gold, as a financial asset, is liquid and can be traded on a futures market. Baur and McDermott (2016) also notes that gold's positive image (bright and shiny) may also contributes to this preference for gold during economic downturns. As a final note, one can suggest, that the coronavirus pandemic belongs to the "Black swan" events (Mandelbrot and Taleb, 2010). "Black swan" events are the unknown unknowns that nobody predicted or foresaw, and they have been characterized as events that carry extreme impacts. These events lie outside the realm of regular expectations and are essentially unpredictable a priori. "Black swan" events, which have never been factored in to risk models, because nobody believed, or predicted that such an event would ever take place, are precisely the type of events that force agents to re-evaluate their portfolios, generating large uncertainties and providing the grounds for safe haven purchases. Events that most closely fit the description of "Black swan" events are the 9/11 terrorist attacks in 2001 and the recent global financial and economic crisis that started in 2007. Regarding the latter, gold prices experienced an intense increase while other assets - and in particular stock prices - exhibited losses (Beckmann et al., 2015), making this way gold a strong safe haven asset. Figure 8 presents diagrammatically the price of oil from 2000 to 2020, where the "Black swan" events are pointed in the diagram.

Figure 8: WTI crude, adjusted for inflation, plotted weekly. Source: Refinitiv by the New York Times

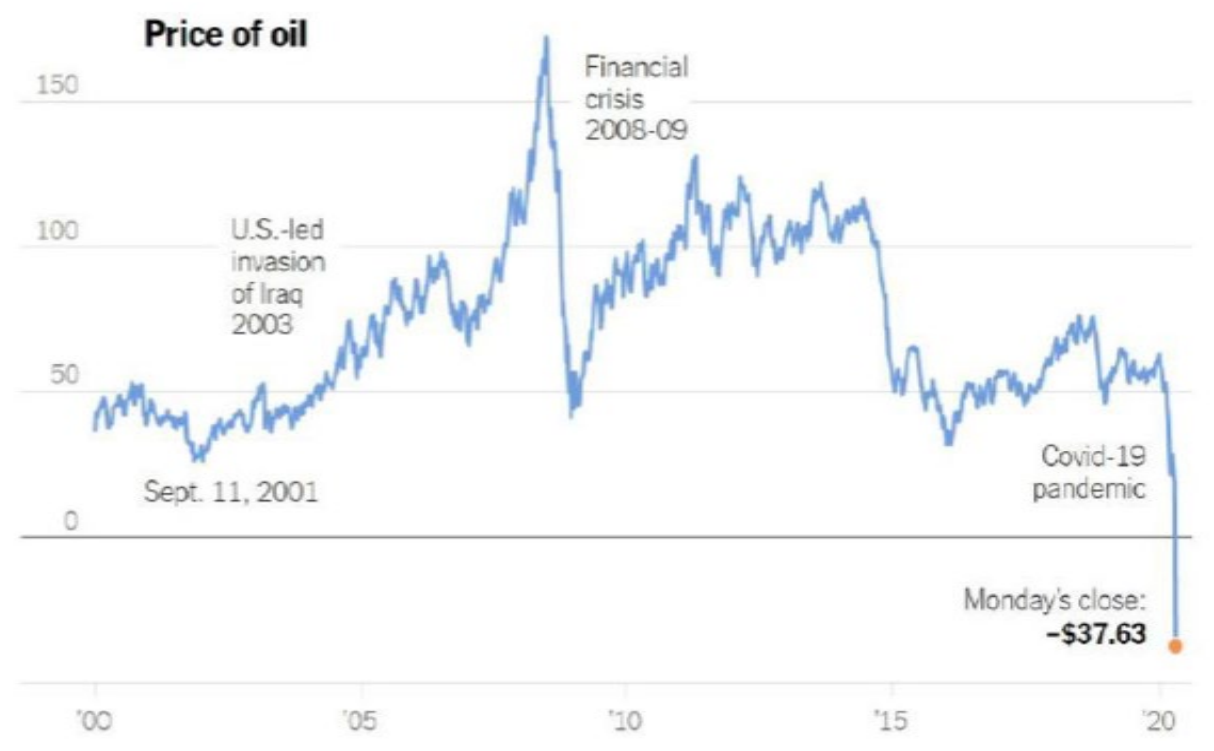


This work appears to be the first that has considered the quantile regressions, along with the market of exchange traded funds (ETFs) and the index of gold's implied volatility, in order to make inferences about gold's hedge and/or safe haven properties One avenue for future research may involve the utilization of alternative flexible quantitative tools such as the nonparametric quantile regressions or the parametric / non-parametric copulas. Given the significant importance of the issue, further research on this elaborate topic is certainly warranted.

Conflict of interest: On behalf of all authors, the corresponding author states that there is no conflict of interest.

\section{References}

Anand, R. and Madhogaria, S. (2012). Is gold a 'safe-haven'? An econometric analysis. Procedia Economics and Finance, 1:24-33.

Anscombe, F. J. and Glynn, W. J. (1983). Distribution of the kurtosis statistic b 2 for normal samples. Biometrika, 70(1):227-234.

Baffes, J. (2007). Oil spills on other commodities. The World Bank.

Baur, D. G. and Lucey, B. M. (2010). Is gold a hedge or a safe haven? An analysis of stocks, bonds and gold. Financial Review, 45(2):217-229.

Baur, D. G. and McDermott, T. K. (2010). Is gold a safe haven? International evidence. Journal of Banking \& Finance, 34(8):1886-1898.

Baur, D. G. and McDermott, T. K. (2016). Why is gold a safe haven? Journal of Behavioral and Experimental Finance, 10:63-71.

Beckmann, J., Berger, T., and Czudaj, R. (2015). Does gold act as a hedge or a safe haven for stocks? A smooth transition approach. Economic Modelling, 48:16-24.

Bredin, D., Conlon, T., and Potì, V. (2017). The price of shelter-downside risk reduction with precious metals. International Review of Financial Analysis, 49:48-58.

Campbell, J. Y. and Hentschel, L. (1992). No news is good news: An asymmetric model of changing volatility in stock returns. Journal of Financial Economics, 31:281-318.

Capie, F., Mills, T. C., andWood, G. (2005). Gold as a hedge against the dollar. Journal of International Financial Markets, Institutions and Money, 15(4):343-352.

Christie, A. A. (1982). The stochastic behavior of common stock variances: Value, leverage and interest rate effects. Journal of financial Economics, 10(4):407-432.

Ciner, C., Gurdgiev, C., and Lucey, B. M. (2013). Hedges and safe havens: An examination of stocks, bonds, gold, oil and exchange rates. International Review of Financial Analysis, 29:202-211.

D'Agostino, R. B. (1970). Transformation to normality of the null distribution of gl. Biometrika, pages 679-681. 
Fousekis, P. (2019). Crude oil price and implied volatility: Insights from nonparametric quantile regressions. Studies in Economics and Finance. 36(2): 168-182.

Hammoudeh, S. and Yuan, Y. (2008). Metal volatility in presence of oil and interest rate shocks. Energy Economics, 30(2):606-620.

Hood, M. and Malik, F. (2013). Is gold the best hedge and a safe haven under changing stock market volatility? Review of Financial Economics, 22(2):47-52.

Joy, M. (2011). Gold and the us dollar: Hedge or haven? Finance Research Letters, 8(3):120131.

Koenker, R. and Bassett Jr, G. (1978). Regression quantiles. Econometrica: journal of the Econometric 4 Society, pages 33-50.

Koenker, R. and Hallock, K. F. (2001). Quantile regression. Journal of Economic Perspectives, 15(4):143-156.

Mandelbrot, B. B. and Taleb, N. N. (2010). Focusing on those risks that matter. The known, the unknown, and the unknowable in financial risk management: Measurement and theory advancing practice, 47.

McCown, J. R. and Zimmerman, J. R. (2006). Is gold a zero-beta asset? Analysis of the Investment

Potential of Precious Metals (July 24, 2006).

Narayan, P. K., Narayan, S., and Zheng, X. (2010). Gold and oil futures markets: Are markets efficient? Applied energy, 87(10):3299-3303.

Reboredo, J. C. (2013a). Is gold a hedge or safe haven against oil price movements? Resources Policy, 38(2):130-137.

Reboredo, J. C. (2013b). Is gold a hedge or safe haven against oil price movements? Resources Policy, 38(2):130-137.

Reboredo, J. C. (2013c). Is gold a safe haven or a hedge for the US dollar? Implications for risk management. Journal of Banking \& Finance, 37(8):2665-2676.

Reboredo, J. C. and Rivera-Castro, M. A. (2014). Can gold hedge and preserve value when the US dollar depreciates? Economic Modelling, 39:168-173.

Sari, R., Hammoudeh, S., and Soytas, U. (2010). Dynamics of oil price, precious metal prices, and exchange rate. Energy Economics, 32(2):351-362.

Shapiro, S. S. andWilk, M. B. (1965). An analysis of variance test for normality (complete samples). Biometrika, 52(3/4):591-611.

Sjaastad, L. A. (2008). The price of gold and the exchange rates: Once again. Resources Policy, 33(2):118-124.

Soytas, U., Sari, R., Hammoudeh, S., and Hacihasanoglu, E. (2009). World oil prices, precious metal prices and macroeconomy in Turkey. Energy Policy, 37(12):5557-5566.

Zhang, Y.-J. and Wei, Y.-M. (2010). The crude oil market and the gold market: Evidence for cointegration, causality and price discovery. Resources Policy, 35(3):168-177. 